\title{
Ideological formation: a study about the influence of contemporary music
}

\begin{abstract}
This research aimed to investigate the influence of hard core style music of the Brazilian band DeadFish, has on the ideological formation of their followers through the internet. The methodology used was quantitative and qualitative. Data were collected online through the Google form containing seven questions designed to analyze how the lyrics of the band's songs interfere with listeners' habits and help them reflect on the manipulation of mass culture. As inclusion criteria, subjects who answered the questionnaire digitally between July 6 and July 7, 2019 were selected. Data collection provided 160 responses that were analyzed using the discourse analysis instrument. As a result of the analysis of the questionnaires it was possible to verify that the audience that answered the survey is not significantly affected by the lyrics of the band's songs, to the point of making them modify consumer habits, as well as not led them to reflect more deeply. about the consumer culture imposed by the mass media. In this sense, the impact on the listeners are focused during the listening of the songs, and the message uttered by the band only lasted the time of the song, configuring itself as a form of entertainment, not surpassing this space, and not coming up with an effective criticism the band itself proposes to perform.
\end{abstract}

Keywords: ideology, social psychology, philosophy of art, cultural industry, contemporary music
Volume 5 Issue I - 2020

\author{
Picanço Jr Álvaro da Cruz,' Alvarenga Renata \\ Caballero \\ 'PhD in Educational Psychology, Postdoctoral Fellow -PNPD- \\ CAPES in Educational Psychology, UNIFIEO-Osasco, Brazil \\ ${ }^{2}$ Degree in History and Philosophy, Professor of the São Paulo \\ State Department of Education, Brazil
}

Correspondence: Picanço Jr Álvaro da Cruz, PhD in Educational Psychology, Postdoctoral Fellow -PNPD-CAPES in Educational Psychology, UNIFIEO-Osasco, Brazil, Email alvaropicanc@gmail.com

Received: November 27, 2019 | Published: January 17, 2020

\section{Introduction}

This work stems from the disquiet arising from the current historical moment in which Brazil is passing: Lack of deeper interpretation of social reality generating hatred, violence and discontent among people, and it is evident that we receive interference from the world that alters our perception of reality. This world I refer to as the show, very well defined by Guy Debord in The Society of the Show (1997) proposing us to reflect on the reasons why we do and are what we do and are.

In recent decades, Brazil is undergoing an intense and worrying transformation in the political, social and cultural scenario, impacting and altering the formation of individuals. Given this complexity and the direct contact with adolescents and young people as an educator in the public school system of the State of São Paulo, committed to an education for emancipation, it is necessary to reflect on the ideological influence that permeates the current scenario in Brazil, since the beginning of pre - 2013 election campaign at the height of fake news.

Contemporary society alienates the individual to maintain power relations thus rendering the understanding of him self and the world empty. It is very likely that a considerable portion of people are concerned with possessing assets by giving them sentimental values and sensations, discarding Being and reducing their interest to Have.

These observations can be seen by any of us through the interactions to which we are daily subjected to. Cultural industry that uses mass media to interfere with our perception, an example of this today is the internet. The Internet is a resource that offers a large collection of information available to users as a search tool for the desired interests. It is an immediate possibility of insertion and access, and can be established as a source of knowledge, but when not fully understood. and purpose we partially absorb and decontextualize information superficially. Thus, the Cultural Industry, by appropriating and combining the dominant forces, redirects a consumer product, unconsciously altering the consciousness of individuals exposed to this standard model. Thus, in order to address the impact of these actions, I intend to analyze the musical discourse as tool of contesting action and rejection of the standardized values of a collapsing society.

Music according to Adorno ${ }^{1}$ clearly expresses the contradictions that exist in society. The ideology present in the cultural industry ends up producing in the subjects an adequate sensitivity to their products. In view of the dimension caused by the perception of the message produced by music, it is evident that not all possible understandings can be elaborated and presented, in this sense we seek to understand how the receiver/listener when having contact with ideas that are punctuated by the musicians. Music producers linked to the real issues - political, social and cultural - experienced and perceived to the point of being melodically translated to reach a group of individuals.

In this context, this research aimed to analyze the influence of musical discourse on the ideological formation of the individual, from the analysis of songs of the band Dead Fish.

\section{Musical ethos}

Music is a cultural manifestation of humanity, is subjective, poetic, educates, stimulates and represses sensations. In addition, music is an element that has been thought by human consciousness to express sounds that can transform the perception of the individual. The vibration of the energy occasioned in musical practice promotes a subjective perception construction of the world to its receiver, as well as the composer of music. 
It is worth noting that besides the harmonic field recognized in the practice and musical performance, she is a voice, and speaks her words contribute to the formation of thought when accompanied by a composition that reflects portraits of the reality lived by its producer, intentionally critical in the social field. in which it is produced and reproduced, that is, it can be understood as an element to ground ideas.

According to musicologist, philosopher and educator Yara Caznok, the music provokes affection, that is, when the composer wants to provoke feelings related to sadness, mourning, introspectively, anguish, etc., first he will choose minor tone / sound, that means that his characteristics are in the range of notes within the "possible" notes on the scale, the larger, solar tones awaken feelings of happiness, joy, euphoria, enthusiasm, etc.

Considering this analysis, Yara adds that the affections caused by music are aroused given the formation of our western ear, based on Descartes' conception. Throughout the history of mankind, music has a purpose in every age, considering that music is part of culture, each people in its time appropriating it and dominating its performance, for example, in societies.

\section{Musical aesthetics}

Musical Aesthetics understands what each technique of composition and performance brings new and pleasant to the human being. The aesthetics applied to music see each musical work as a speech, a written text made up of sentences, paragraphs and words. It is interesting here to understand the sound forms and their action on the individual, emphasizing that one does not listen to music only with the ears ${ }^{2}$ to establish the guiding line between the relation melody and expression on the perception of the receivers. 2004) divides the music into two genres: popular music and artistic music. According to his thesis, popular music is a form of culture that replaces "difficult" and critical music that would generate reflection on social life. The false needs created by the Cultural Industry can be supplied by the capitalist system by encapsulating the individual into notions of dishonest beauty, or in his words:

There is a historically pre-established harmony between the material need to compose on demand, the necessity that is due to unbend ability, and it is this relaxation of the inner tension that makes the composer able to carry out - thanks to the technique of the autonomous work of art, conquered with indescribable. fatigue heteronomous work, relaxation that at the same time separates it from the truly autonomous work. This tension that is resolved in the work of art is the tension between subject and object, between interior and exterior. $^{3}$

This means that the process in which creation occurs requires the interconnection of elements of the individual who composes it, the medium, and the recipient of the message, thus contributing to an artistic production that is carried out in order to substantiate something.

It is understood that what causes the producer to create is linked to his understanding of the world and the attitude he takes in committing himself to what will become a work, a work that requires from its creator a process to be realized, thus Perception experience is linked to the establishment of certain conditions of the producer in order to provoke the listener, the accumulation of memory, the experience in the world builds a reflection of what the producer understands, therefore the process of creation is not only individual, it is temporal and space Each epoch has its music and its contemporaries will focus on their understanding, in this sense it is pertinent that the composer puts himself as part and not out of the sense he intends to provoke in the listener.

\section{Contemporary musical styles}

The questions related to the new music worried Adorno, ${ }^{1}$ for the author it was difficult to understand this new music by the distance between her and her listeners. Given the cultural industry as the annihilation of culture, the new music treated as a commodity results in the subtraction of the listener's contemplative autonomy, that is, the listeners' tastes and the musical objects themselves have become degenerative.

In Adorno's conception the musical reasons are not dissociated from the social ones, thus allowing us to understand the difficulties of understanding new music. This music comes without the commitment to be understood, does not provoke in the listener (receiver) assimilation capacity, it is mainly based on the behavior perpetuated by mass cultures "[...] everything that comes to public is deeply marked that nothing can arise without displaying in advance the traces of jargon and without accrediting the approval of the first look".

It happens that a whole media structure to promote commercial music is built, the cultural industry determines what will be the "new hit of summer" and inserts in its programming grid the musical trend that will hit. This process creates a new type of $\mathrm{k} 7$ tape listener (receiver) to digital platforms. Commercial music has been perpetuated in recent decades, transforming the concept of listening to music. According to Adorno it means that " $[. .$.$] to the extent that$ a musical object has recognition and fame, becoming a fabricated success, it is more esteemed by public opinion". ${ }^{4}$

The media promotes this showcase and drives the choices the consumer (listener) will make, that is, public opinion influences the commercial music that will be reproduced thus creating stars and musical idols, giving them prestige and success;

Consumers, seeing the success panel, feel inclined to own the goods offered less because they have evaluated the actual composition of the object, but in a degenerate manner, consume the merchandise by attracting the value commercially installed by the media. ${ }^{4}$

It is, therefore, in this new mechanism that contemporary music is located where technologies have transformed the relationships between individuals, changing the thinking about art and its cultural impacts, the fetishism in music can be identified from the observation of how music is transformed into an object of enchantment that does not generate reflection in its manifestation, but is administered in a way that represses the listener's emotions, becoming a product consumed as idolatry.

\section{Methodology}

The present work is inserted in the field of qualitative research defined as an exploratory research. Data collection was performed by digital questionnaire, among the band followers. Inclusion criteria included subjects who answered the questionnaire digitally between July 6 and July 7, 2019, which was made available through the "Google form" containing seven questions designed to analyze the listeners of the band and their relationship with speech musical. The quiz link was made publicly available via social network (Facebook) 
in a group (online- DeadFish Official) of fans/admirers of the band that has almost ten thousand members, getting 160 answers. Thus, the data collection instrument was based on the open-ended questionnaire, identifying different conceptions by the respondent.

The questions were designed to understand and interpret indicators regarding the age range of the listeners, the medium that made them reach the band, and how the message relates to their individualities. In this sense, the questions are complementary and will be analyzed together to clarify the listener profile and its relationship with the musical discourse. As an object of investigation for the questions, was selected the lyrics of the song Dream Medium that is in the album of the same title released by the band in 1999 .

After the data obtained, the investigation process was performed and the answers obtained were analyzed in order to identify the important information about the perception of the individual in contact with the music and how it interferes in the ideological formation of the music. The sample was important for the researcher to reach consistent conclusions. In relation to the research carried out, the attached questionnaire has a reflexive character in which Franco ${ }^{5}$ points out The respondent not only responds to the information sought, but also faces provocative questions, creating the opportunity to reflect on their living conditions, as a product of a contradictory social structure. ${ }^{5}$

In this sense we seek meaningful songs, in order to understand the content of the worldview expressed by the band's composers, the tonic of the songs lies in themes such as the capitalist consumerism criticism and the ideological manipulation promoted by the ruling classes.

\section{Data collect}

In an attempt to analyze the ideological influence that music allows to affect the receiver listener, it is necessary to present the data based on an investigation that aims to identify the content and the impact that this message affects by the statements in the musical discourse. Thus it was possible to observe the listener's perception and the contribution of the message found in the DeadFishan band's musical discourse by analyzing to what extent the discourse affects, establishes, transforms its relations between sender and receiver.

\section{Deadfish band}

In the historical context that DeadFish surge have a decade after the civil-military dictatorship coming to an end, the 90s transformed the world and Brazil inaugurating a new social political model, within the economy the expansion of neoliberalism and trends technology being announced, a scenario of uncertainty as a repressive and objectionable state structure in ideas, music represents this direct contact with its time, direct vote for the president's choice, Plano Color, student movements, inflation, impeachment, ECO92, population extermination vulnerable, Real Plan, FHC, MercoSul and a growing foreign debt devaluing our currency, in an environment with these influencing factors Dead Fish's musical discourse, so these external elements are directly linked to the band's compositions, where the album Middle Dream born in 1999 and conquers space in the Brazilian underground scene.

Music in scenarios such as these of troubled moments experienced by the country allows us to present the conflicting articulations of social life, and through this message Dead Fish builds indignation with quick chords and ironies in its utterances, but with a well-defined positioning and marked with a radical stance the political issues of the individual. With its reflections on general problems of human life and society Hard Core is there giving voice to the discontented of an unequal state:

\section{"Middle Dream Dawn once again/}

\section{It's time to wake up to win/}

\section{And have something to tell someone to send/}

\section{A life to order, to accumulate"}

The illusion in the search for a social position in a consumption space that is incorporated in the Brazilian society as a goal of a full life are the factors experienced during the 1990s, directly influenced the masses mentalities that are stimulated, above all, by the great media and the technological expansion of internet access, this daily routine of an average life, subordinated to the rules imposed by the market and the satisfaction of accomplishment through this model of life, is the criticism presented in this paragraph as provocation of discourse.

\section{"And then live. Live and prosper/}

\section{Nothing more to think about. Me myself and I/}

\section{And so remain. Credicard, status quo/}

\section{That's all I think it is, illusion is questioning"}

The status quo desired by the individual infected by capitalist ideology puts him in the status of giving up questioning to consume without reflection. A quote from a credit card brand sums up the stimulus to buy in installments the instant happiness of a lifetime for consumption, but what is the value of it? How many installments do you want, sir?

Still including the spread of thinking only in itself, the rule of liberalism, ideologically, "you are solely responsible for its success," and in this sense musical discourse proposes this questioning to the listener, this thinking alienates the individual from his own identification. social, distances him from the collective, and makes him take on the incessant dispute of consuming without understanding why he does what he does and to remain in this position is alienated about his own condition.

Ideology, as an objectively necessary and at the same time false consequence, as an inseparable intertwining of truth and untruth, which is thus distinguished both from total truth and from pure lies, is indeed justification. It presupposes, therefore, whether it is the experience of a social condition which has become problematic and known as such, but which must be defended, or, on the other hand, the idea of justice without which that apologetic need would not subsist. ${ }^{1,2}$

Shopping malls are contemporary temples, where fruition, desire and compulsion are deaf passions to any rational arguments. Buying is a new dogma that sustains, through infantile satisfaction, rational economic behavior: one no longer works only to live, but to buy, because to buy more and more is to live. ${ }^{6}$

It is evident that the discourse leads us to criticize the feeling of abundance of consumer goods symbolizing the act of going to the mall to spend the satisfaction of belonging, the production of meaning and symbolic processes makes the individual hostage to this expectation placing him as an active consumer or not in this reality, 
and thus defining it socially, the final years of the 90s in Brazil the mall becomes a social status in the lives of individuals, so Dead Fish conducts its narrative mocking the new market trends.

"Have and always believe. Beginning, middle and end/

\section{Hypocrisy will win, I will smile at you/}

It will be a party amid chaos and ugly people will pay/

For we are the elect, at least we think we are/

\section{Our race is superior, but I'll pretend to be that color"}

Feeling destined for a privileged place where the group that a particular individual is inserted into is necessarily better than the group that is not, the racial prejudice quoted in the sentence demonstrates that Brazilian society is divided between whites who live in an economic class and blacks who should serve those at the top of these social hierarchies, the reflection of this passage causes uneasiness in our thinking as a society, in thinking about the existing subdivisions and how we neglect the other by judging him or maintaining discourses that legitimize racial discrimination, extremely important agenda.

\section{"Roberto Campos is our guru/}

\section{And forever we'll be liberal to work, to live!"}

The figure attacked in the discourse is a symbolic representation of a political / economic movement that the process of creation of composition is inserted, the clash is straightforward, there is a scenario to be questioned, because there are ideological forces that overlap the will of individuals, distant from the historical moment in which the composition was produced, allows us a deeper analysis, as a source of a historical moment, to think about the impacts of the economic policy directly in Brazil over the last twenty years, that is, from where it is observed Musical discourse can provide us with results that neoliberal politics achieved during its execution, and that Roberto Campos' proposal can be analyzed and concluded by those who wish to However, in this paragraph the speech is straightforward, mocking the picture of the actions the ideas of this picture represent in the context of the average dream.

\section{"It doesn't matter if my kids won't have an education}

\section{They have to have money and look "}

This situation can be observed in the middle class, little appreciation of education, absence of parents in children's lives, accumulation of consumer items, updated models of mobile phones, cars of the year, destroying the possibilities of achievement of the individual in their potential and convincing. of belonging to an alienated life whose purpose is to fit into a predetermined social pattern. For Adorno and Horkheimer "this adaptation takes place through the products of the cultural industry." 1,2

\section{"The average dream will, will conquer you/}

\section{Plastic mindset and a caring image"}

For Ramos " [...] in order to have enchantment, the subject must be lost in the immediate experience with the object, without losing it subjected to rationalized means or emptied in its own formalization". ${ }^{6}$ It means that being absorbed by the consumer products of the cultural industry empties the critical sense of the individual by transforming his perception and appreciation, so whatever is ideologically designed as a status to be achieved must be sought, because interest is capital and social construction. that the individual occupies in society, even if it is only the fantasy created for the relentless competition to conquer illusion investigate.

Thus, the individual anesthetized and bombarded by the criteria set by the cultural industry avoids being judicious about what they consume and accepts the products available for their entertainment.

\section{Results and discussion}

It is up to the data to analyze the relationships that the individual listening DeadFish band through communication established with the discourse between receiver and music shows that the process happens according to the social context in which the individual is, the research reveals that listeners' awareness is related to the position/status that this individual occupies and the way it relates to the content proposed in the discourse (Table 1)

Table I Age of band listeners. Prepared by the authors

\begin{tabular}{ll}
\hline Up to 18 years old & 0 I answer \\
I 8 to 21 years old & 13 answers \\
22 to 27 years old & 55 answers \\
28 to 33 years old & 72 answers \\
34 to 40 years & 16 answers \\
40 years old & 01 answer \\
No Answer & 0
\end{tabular}

Observing the age of the listeners from the sample shows that the age group between 22 and 33 years is in the majority, being more than half of respondents. What indicates in this section is that the age of the listeners of the band is related to youth, youth can be understood as a phase that every human being is exposed to perform in their existence, thus, it is noted that this social group exercises a role in society and yet is determined by an adult society performing various tasks and assuming determinations throughout its phase. Youth have specific traits that define them through symbolic expressions through their representations of themselves and the world. Deny rituals of a pattern of behavior.

A question raised during the observation of the results was the attraction that a certain age group has with the discourse message, when the contact with the band occurs; the individual assigns an identification with the proposal / theme that may occur in the youth for this occasion. to be part of a tribe, a tribe here understood in the form of membership, in this case of constantly renewing young people, to find a place in the world that defines it and in the case of Hardcore an culture the identification linked to collective unrest where their political views and thoughts about the posture of certain groups are questioned.

The average time that the individual is in contact with the musical work is around one third of the listeners, 65 answers were obtained claiming to listen to DeadFish songs for over 15 years, considering this information it is understood that the listeners had his contact with the band before 2004, followed by 57 respondents who consider having met the band from 2004 to 2009 . 
When we analyze the age and time that the individual listens to the band, it is evident that this average reveals that the listeners possibly got to know the songs through mass filters, or in the contact established with people close to the circle of coexistence.

When referring to mass filters, I would like to point out that in 2004 Dead Fish gained access to a structure with greater capacity to transmit the message, having its image linked to the media like MTV (Table 2).

Table 2 Song Message Identification Elaborated by the authors

\begin{tabular}{ll}
\hline Criticize the middle class & 56 answers \\
Alienation / Capitalism & 25 answers \\
Consumerism & 22 answers \\
Irony & 08 answers \\
Economic Liberalism & 07 answers \\
Behaviors / values & 06 answers \\
Social Status & 03 answers \\
Individualism & 02 answers \\
Social Classes & 02 answers \\
No answers & 4
\end{tabular}

The ideological influence provided in the relationship established between receiver $\mathrm{x}$ message $\mathrm{x}$ emitter is the ideology that of the society of semi-information itself - establishes a limited knowledge as the truth. We can observe, in view of the answers obtained in this section, that the song arouses visions of the same structure that is related to capitalism, all the concepts used by the respondents can be found in the capitalist theory.

Even so, all the groupings of the categories are directed to a specific element in the subjectivity of the individual/listener, the individual experiences, their experiences, their way of seeing and being in the world contribute to their perception in listening to the musical discourse. The individual is the reproduction of the social environment that is inserted, and where it was built as a social being. Inserted, therefore, in a place ideologically formed by the semi formation its conception is linked to its time.

The consideration in this section allows us to observe that listeners assign meanings to the way they interpret the song and define it through their perception and relationship with music, discourse favors identification with a set of ideas.

In the category "Others", the identification of the respondents grouped in this item refers to how their statements about the theme were expressed or why they escaped the objective response presenting disconnected information.

As age levels differ in the composition of the survey, I consider it relevant to think that the answers may be linked to the age of this listener, ie answers in the critical item the middle class (56 answers) can be understood by a more recent audience. band or a group of listeners who built over time the accompaniment of the band this interpretation? Is this perception influenced by time or immediate?
As if listening to the music, the message uttered by the band only lasted the time of the song and thus its consumption would be reduced to the moment of its performance, as a form of fun or entertainment, not surpassing this space, and not giving rise to an effective criticism that the band itself proposes to perform.

Thus, by socially perceiving the individual seeks to break with the determinations that do not arouse belonging in a group. In this section it is possible to group the positive responses demonstrating that the listeners yes are influenced by the musical discourse, when they affirm that this filter interferes with their perception of the world.

Thus, DeadFish's musical discourse is related to the identification of the message where it enables the individual to change their social relationships and their formation throughout life.

It does not mean that the answers result in a determination, but considering the diversity of possible opinions in some way what contributes in this section is to realize that the individual is putting himself in a position of questioning about the thought that comes to him through music, causing discomfort to him. point of provoking the individual to seek further clarification. Which seems to be one of the reasons why the band continues to deliver reflective musical discourses (Table 3).

Table 3 About the political positioning of the band .elaborated by the authors

\begin{tabular}{ll}
\hline I agree & 4I Answers \\
Disagree & 04 Answers \\
Coherent / positive & 48 Answers \\
Behavior Change & 03 Answers \\
Essential due to HardCore & 27 Answers \\
Partially considers placements & II Answers \\
Relates to the current moment & I7 Answers
\end{tabular}

The criterion of this section corresponds to behavioral changes, music is power over people, its communication establishes a dialogue and so the interference of the political positioning that abandons is oriented in a way is a concern for its listeners. 89 respondents consider positive, or agree with the position taken by the band, which may mean that there is an understanding of the song guidelines, so the speech is understandable, another data extracted from this section is to have 27 answers that consider the positioning, This demonstrates that the listener in his conduct, his representations, his values, affective and social experiences analyzes the conditions in which the discourses that the band transmits is situated, thus the expression of the existence of the band has a meaning and a meaning that possibly matches the expectations of the listener.

\section{Final considerations}

After conducting the survey of theoretical references and data collection through questionnaire and interview, it is possible to reach some very important conclusions about the role of music in the individual's daily life and its communicative relationship.

The development of this study made it possible to interpret the model of life based on consumer goods, starting from the observations of the environment in which I live, it was possible to perceive the 
direct connection we have in relation to music, and its existence is present as a form of expression and expression. Knowledge of what we are as human beings. Thus, the music exerts power over the listener enabling sensations and, as speech conveys a message, in this case the music of the band Dead Fish was analyzed to demonstrate that, from the contact with the musical discourse the utterance invites the listener to dialogue, In this way, the sender establishes through communication a communication, in this case, a provocation to the receiver that can propose to reflect on the message.

Understanding musical discourse as enabling for the attainment of new behaviors and with new needs as they establish new daily habits, relationships change, the construction of discourse by the sender/ producer requires that its enunciation present potential information to dialogue with the receiver /listener.

In this relationship there are impacts on the language space determining identifications by the individual, this approach in a scenario of standardized patterns that is intensified by the cultural industry, allows to reflect on the conditions of the construction of the musical discourse, since the culture industry determines trends and creates music for mass consumption contemporary society has its nonconformist reactions, they emerge with thoughts of contesting social behaviors, engaged approach and against consumerism.

Considering what has been observed, the cultural industry forms a public and from its ideological construction these individuals form their ideology about their understanding by music, which demonstrates here is that in the sense of the specific look of the Dead Fish band's musical discourse it was possible to analyze that the discursive aspects identify that the speaker has something to say. By identifying the theme, the dialogue is explored.

The individual who becomes aware of the relationship he establishes with the musical discourse considers it important to be engaged, music allows everyday experiences to put him in reflection on the guidelines approached in the song, the valorization of ideas that enable criticality is a channel of possibility. to break with the maintenance of the image of a society for all, when the capacity for transformation depends not only on the will but for structural changes in society. Music enables us to understand cultural, social and historical aspects, especially revealing the permanence of social inequalities.

Investigating the impacts that musical discourse has on individuals demonstrates the importance of understanding music as a form of communication, a language, which through its meaning carries relationship with their social context, and enables individuals to construct their meaning individually and collective way.

\section{Acknowledgments}

\section{CAPES}

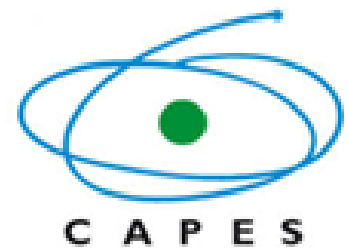

\section{Conflicts of interest}

The authors declare that there is no conflict of interest.

\section{References}

1. Adorno Theodor W, Horkheimer, Max. Dialectic of enlightenment. Philosophical fragments. Editora Zahar, Rio de Janeiro; 1985.

2. Harnoncourt, Nikolaus. The speech of sounds. Zahar, Rios de Janeiro; 1990.

3. Adorno Theodor W. Philosophy of new music. São Paulo. ed. Perspectiva; 2004

4. Adorno Theodor W. Fetishism in music and the regression of hearing. In: The thinkers In: Os Pensadores - Theodor W. Adorno. Texts . São Paulo: nova cultural; 1996

5. Franco MLPB. Ensino Médio. Challenges and reflections campinas. São Paulo, 1994.

6. Ramos Conrado. Cultural industry, Consumerism and the dynamics of satisfaction in the managed world. In; Durâo, Fabio A. editors. (Org). The cultural industry today editora bom tempo. São Paulo. 2008. 